\title{
Teaching Materials for Engineering Education in High School from the Increase of Working Fluids in Electrospinning
}

\author{
Wenbing $\mathrm{Li}^{1}$, Zhu Zhang ${ }^{2}, *$ Guanghua Wang ${ }^{1}$ \\ ${ }^{1}$ School of Chemistry \& Chemical Engineering \\ ${ }^{2}$ Department of Internal Medicine, Hospital of WUST \\ Wuhan University of Science \& Technology \\ Wuhan430081, China \\ zhangzhu75@wust.edu.cn
}

\author{
Tianyu $\mathrm{Li}^{3}$, Sujuan $\mathrm{Zhou}^{3}$, Deng-Guang $\mathrm{Yu}^{3}$ ** \\ School of Materials Science and Engineering \\ University of Shanghai for Science and Technology \\ 516 Jungong Road, Shanghai 200093, China \\ ydg017@usst.edu.cn
}

\begin{abstract}
Scientific innovation is often reflected in the engineering processes. On the contrary, the engineering processes hidden in advanced technologies can provide many vivid teaching materials for effective innovation and engineering educations to the college students in high school. In this paper, we conclude the advancement of electrospinning processes, which is fast developed from one-fluid blending process two decades before to two-fluid coaxial electrospinning, and now develops three-fluid tri-axial electrospinning. The increase of working fluids in electrospinning is useful for college students to provoke their interests in advanced nanotechnologies. Meanwhile, the increase of working fluids in electrospinning is also excellent teaching materials for the students to build linkages between their previous knowledge and new technologies, so deepening their comprehensions on them. What is more, the increase of working fluids in electrospinning is excellent teaching materials for the students to learn how to implement innovations all by themselves, such as engineering design innovation, analogical innovation, and innovation of analytical methods.
\end{abstract}

Keywords-Teaching materials; Innovation education; College students; Electrospinning; Working fluids

\section{INTRODUCTION}

Today, the fast development of science and engineering require that the college students have a well grasp of the related advanced technologies within their majoring fields, who aim to become an excellent engineer in future in the society. For students from the disciplines focusing on science and technology, on one hand, the preparation and characterization technologies comprise the most important contents that they should learn in their senior grades in the university. On the other hand, numerous vivid teaching materials can be refined from these advanced technologies for a better engineering education and improving their innovation capability. Or in other sentence, advanced technology can provide a fine platform for the integration of engineering education and innovation education (Fig. 1A).

In a concrete engineering education about the materials, the advanced technologies can shine their lights on a series of teaching areas about the related knowledges. These knowledges include the material science, the scientific theories about preparation, the mechanisms about the working processes utilized to treat the raw materials, the related processing methods and the exploited tools, and also some key issues in the future development of a certain discipline (Fig. 1B).
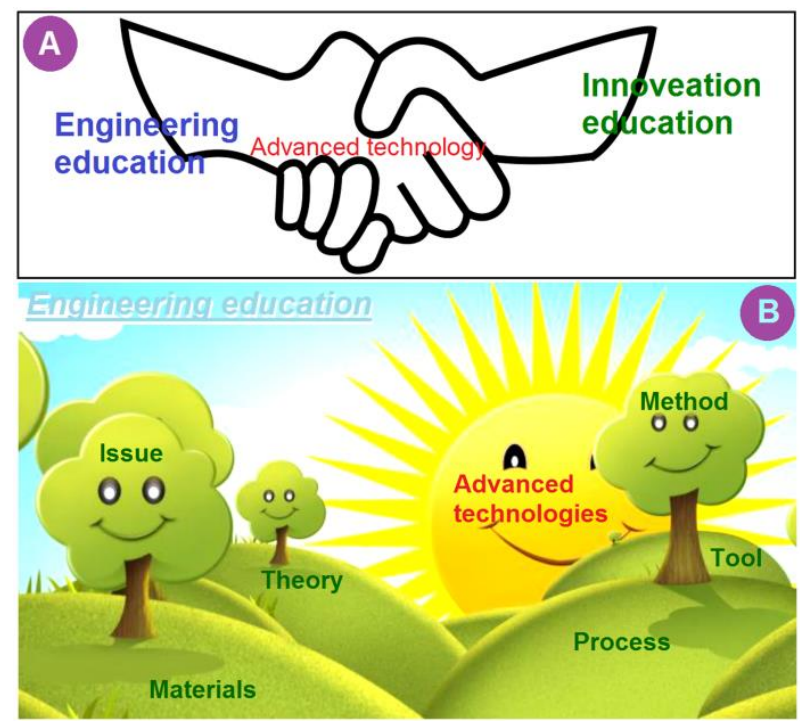

Fig. 1 Advanced technology can provide a joint point for both engineering education and innovation education in high school (A), and it always shines lights on the engineering educations to undergraduate students.

As a nano era, the advanced technologies frequently occur in the field of nano science and engineering. The two main categories of nanotechnologies are "top-down" and "bottom-up" nanofabrication methods with a very small section of advanced nanotechnologies taking a combined manner of "top-down" and "bottom-up" processes [1]. Electrospinning, derived from electrostatic spinning, is a typical "top-down" process. This nanotechnology has a series of unique properties making it very popular in the present scientific research fields and also in the potential industrial applications [2-7]. These properties include a very simple 
process (one-step), a straight forward manner to create solid nanofiber, very cost, and excellent properties of the resultant nanofiber non-woven mat [8-13].

During the past two decades, the electrospinning technology has developed from the traditional single-fluid blending electrospinning process to the double-fluid coaxial and side-by-side electrospinning processes, and now is fast developing to the three-fluid tri-axial electrospinning processes and some complex processes characterized by a combination of coaxial and side-by-side processes [14-21]. In 2002, the coaxial electrohydrodynamic atomization (EHDA) process was first reported by Loscertales et al, which is essentially about a traditional coaxialelectrospraying process [22]. Later in 2004, Dzenis declared that coaxial electrospinning is one of the most important breakthroughs in this field [23]. Most recently, the even complicated tri-fluid coaxial electrospinning was demonstrated to be useful in creating tri-layer nanofibers [24]. A diagram showing the development of new kinds of electrospinning processes is given in Fig. 2. The more the working fluids involve simultaneously, the more complicated the electrospinning processes are. Meanwhile, excellent teaching materials can be refined from this development process for effective engineering and innovation education for college students in their senior years in high school.
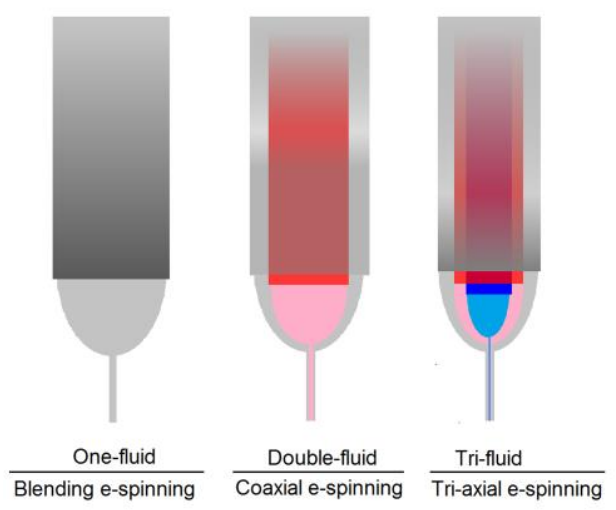

Fig. 2 The new kinds of electrospinning processes: the increase of working fluids treated simultaneously during electrospinning represents advancement in this field.

II. THE INCREASE OF WORKING FLUIDS IN ELECTROSPINNING IS USEFUL FOR COLLEGE STUDENTS TO PROVOKE THEIR INTERESTS ABOUT ADVANCED NANOTECHNOLOGIES

First of all, the increase of working fluids simultaneously treated in electrospinning will bring out interesting phenomena, which is very useful to provoke the students' interests about the advanced nanotechnologies, and to make the explanations of electrohydrodynamic mechanisms to the students easier and more vivid.

Shown in Fig. 3 are a series of phenomena captured using camera under a certain magnifications. Fig. 3A gives a typical electrospinning develops processes, i.e. the formation of a Taylor cone, followed by a straight fluid jet, and later a bending and whipping process is initiated with gradually enlarged loops. Fig. 3B and Fig. 3C are Taylor-cone-straightfluid-jet-bending-whipping processes of coaxial and tri-axial electrospinning processes, respectively. Apparently, these processes are similar in the developing processes. This is because that the processes reflect the interactions between the working fluids and the electrical fields, which has the similar mechanism regardless of the number of working fluids.

However, when the Taylor cones are further enlarged, the differences can be discerned. A single Taylor cone with an even blue color can be read from Fig. 3A for the single-fluid blending electrospinning process. However, a two-layer and a tri-layer compound Taylor cone can be observed clearly for the coaxial electrospinning and tri-axial electrospinning from Fig. 3D and 3E, respectively. The similarities and distinctions of one-fluid, two-fluid and three-fluid electrospinning processes can greatly impact the students, make them go ahead from "look, hear, listen" to "think why" and finally to "try how", increasing their willing in engineering studies.

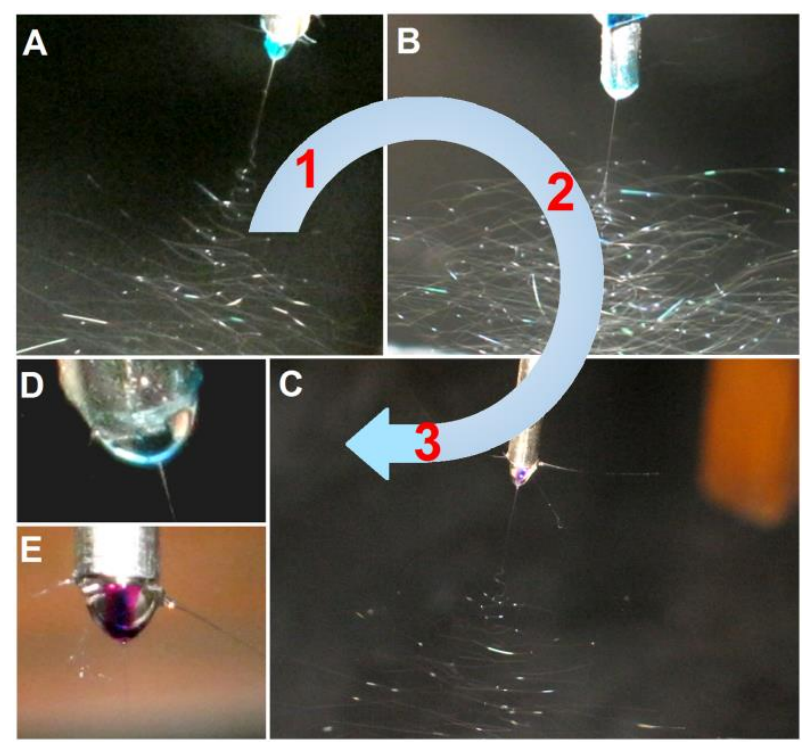

Fig. 3 The phenomena about the increase of working fluids during electrospinning: A) single-fluid blending electrospinning; B) double-fluid coaxial electrospinning; C) tri-fluid coaxial electrospinning; D) Core-sheath compound Taylor cone; E) Tri-layer core-sheath Taylor cone.

\section{THE INCREASE OF WORKING FLUIDS IN ELECTROSPINNING IS EXCELLENT TEACHING MATERIALS FOR THE STUDENTS TO BUILD LINKAGES BETWEEN THEIR PREVIOUS KNOWLEDGE WITH NEW TECHNOLOGIES, TO DEEPEN THEIR COMPREHENSIONS ON THEM}

Besides provoking interests of the students, the teachers can make full usage of the electrospinning advancements to promote them to link their previous professional knowledge with the new techniques. It is anticipated that these linkages would effectively deepen their comprehensions on these advanced technologies.

For example, the initiation of electrospinning process is always a balance between the electrical field $(E)$ and the 
surface tension of working fluid $(\gamma)$ regardless of the simultaneously treated working fluid number. For the singlefluid blending electrospinning, it is ease to grasp for only one working fluid and only one air-liquid interface. However, when the working fluids increase to two and three kinds, a series of air-liquid and liquid-liquid interfaces would appear. This is to say that a series of interfacial surface tension will play their roles in the electrospinning processes, such as outer air-sheath-liquid surface tension $\left(\gamma_{\mathrm{o}}\right)$ and core-sheath fluids interfacial surface tension $\left(\gamma_{\text {inter }}\right)$, shown as Fig. 4 . The explanations of these contents would be useful for the students for better understanding the reason that an "apparent" and "simple" increase of working fluid number from one to two can be thought of a very important breakthrough. Meanwhile, these contents should let them to take this chance to review their previous knowledge about this and other disciplines such as polymer science, physical chemistry, fluid mechanics, interfacial chemistry, and rheology.

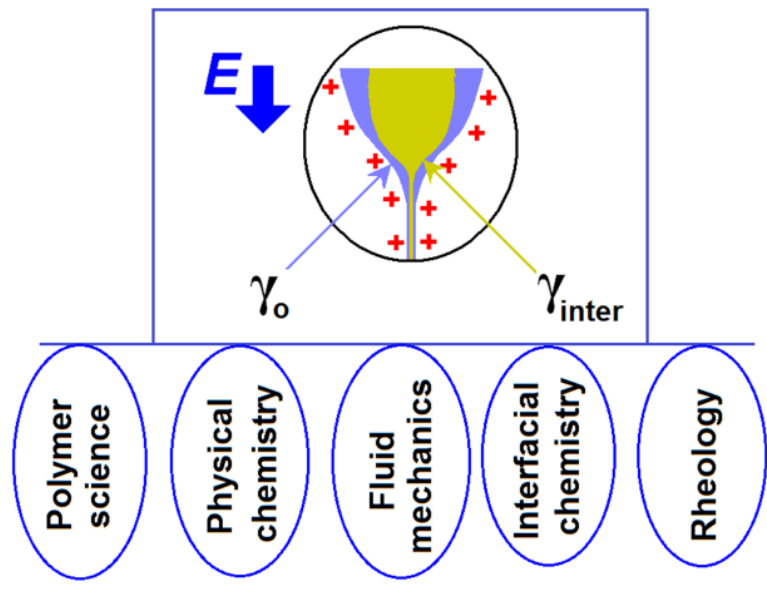

Fig. 4 The increase of working fluids for lessons have a close relationship with their knowledge background and thus it is easy to promoted them to build linkages between their previous knowledge with new technologies, to deepen their comprehensions on them.

\section{THE INCREASE OF WORKING FLUIDS IN} ELECTROSPINNING IS EXCELLENT TEACHING MATERIALS FOR THE STUDENTS TO LEARN HOW TO IMPLEMENT INNOVATIONS ALL BY THEMSELVES

Innovation can be defined as something original and more effective. It is often viewed as the application of better solutions that meet new requirements, which is accomplished through more-effective products, processes, services, or technologies. Scientific innovation is related to (but not the same as) invention, this is because it is more apt to involve the practical implementation of an invention to make a meaningful impact in the related disciplines. It is often manifested via the engineering process, when the problem being solved is of a technical or scientific nature. Thus, for the advancements of electrospinning from one fluid to two fluids and finally to three fluids, a series of different kinds of materials can be explored for both engineering and innovation educations on the college students, guiding them to implement innovations all by themselves.

Shown in Fig. 5 is a diagram that three directions can be utilized for expanding innovation educations. One is about the engineering design innovation, a series of raw materials can be similarly utilized to try the electrospinning processes for preparing new types of nanofibers. These variations include the applied solvents, the additive surfactants, salt little chemical molecules, lipid and also other polymers besides the filament-forming polymer matrices. The second is about the analogical innovation of similar technology, for example, the single-fluid electrospraying can be developed to two-fluid coaxial electrospraying, and to tri-fluid coaxial electrospraying [25-29]. The third is about innovation of analytical methods. Not only new methods can be introduced into the analyses of the as-prepared nanofibers, but also different kinds of characterization methods can be organized together for fully and completely characterizing the final nanoproducts, such as scanning electron microscope (SEM), transmission electron microscope (TEM), X-ray diffraction (XRD), differential scanning calorimetry (DSC), and some other functional application analyses.

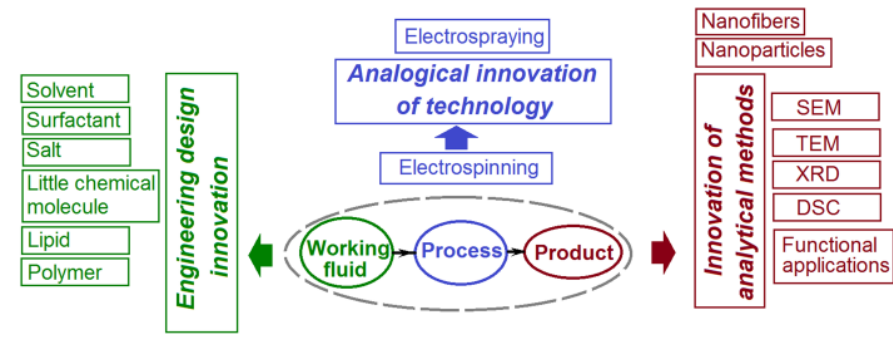

Fig. 5 "The increase of working fluids" in lab experiments can effectively lead them to try new experiments all by themselves, and fostering their innovative capability.

\section{SUMMARY}

A series of teaching materials are successfully refined from the advancement of electrospinning processes, which is fast developed from the one-fluid blending process two decades before, to two-fluid coaxial electrospinning, and now the three-fluid tri-axial electrospinning. These vivid teaching materials is not only useful for provoking college students' study interests on advanced nanotechnologies but also is an efficacious manner for the college students to build linkages between their previous knowledge with new technologies and to deepen their comprehensions on the advanced technologies. Three directions can be explored form the progresses of electrospinning for expanding innovation educations, engineering design innovation, analogical innovation of similar technology, and innovation of analytical methods. 


\section{ACKNOWLEDGMENT}

The financial supports from the following projects are appreciated: the Shanghai Education Science Research Project (C17058), the National Natural Science Foundation of China (No. 51373101), the 2017 Graduate curriculum reform project in USST, the College Student Innovation Project of USST (Nos.SH2018), and the Scientific Research Project of Education Department of Hubei Province (B2017001).

\section{REFERENCES}

[1] R. Ghosh Chaudhuri, S. Paria, "Core/shell nanoparticles: classes, properties, synthesis mechanisms, characterization, and applications," Chem. Rev., vol.112, pp.2373-2433, 2011.

[2] Q. Wang, H.P. Li, C. Yang, J.J. Li, and D.G. Yu, "Beads-on-a-string amorphous solid dispersion fabricated using a modified coaxial electrospinning," J. Control. Release, vol.259, pp.e111-e112, 2017.

[3] D.G. Yu, H.P. Li, C. Yang, J.J. Li, Q. Wang, and G.R. Williams, "Double-pulsatile release core-shell fibers fabricated using modified tri-axial electrospinning," J. Control. Release, vol.259, pp.e24-e25, 2017.

[4] J.J. Li, Chen Yang, Hai-Peng Li, Qing Wang, and Deng-Guang Yu, "Oral controlled release in accordance with drug adsorption biological rhythm provided by an electrospun structural amorphous solid dispersion," J. Control. Release, vol.259, pp.e61-e62, 2017.

[5] Y.H. Wu, D.G. Yu, H.P. Li, X.Y. Wu, and X.Y. Li, "Medicated structural PVP/PEG composites fabricated using coaxial electrospinning," e-Polymers, vol.17, pp.39-44, January 2017.

[6] D.G. Yu, C. Yang, M. Jin, G.R. Williams, H. Zou, X. Wang, et al, "Medicated Janus fibers fabricated using a Teflon-coated side-by-side spinneret," Colloid. Surface B, vol.138, pp.110-116, Feburary 2016.

[7] X. Liu, W. Shao, M. Luo, J. Bian, D.G. Yu, "Electrospun blank nanocoating for improved sustained release profiles from medicated gliadin nanofibers," Nanomaterials, vol.8, Article ID 184 (11 pages), 2018.

[8] Y.H. WU, H.P. Li, X.X. Shi, J. Wan, Y.F. Liu, and D.G. Yu, "Effective utilization of the electrostatic repulsion for improved alignment of electrospun nanofibers," J. Nanomater., vol.2016, Article ID2067383, 2016

[9] G.Z. Yang, H.P. Li, J.H. Yang, J. Wan, and D.G. Yu, "Influence of working temperature on the formation of electrospun polymer nanofibers," Nanoscale Res. Lett., vol.12, Article 15, January 2017.

[10] Y.Y. Yang, Z.P. Liu, D.G. Yu, K. Wang, P. Liu, X. Chen, "Colonspecific pulsatile drug release provided by electrospun shellac nanocoating on hydrophilic amorphous composites," Int. J. Nanomed., vol.2018, DOI: 10.2147/IJN.S154849, 2018.

[11] Q. Wang, D.G. Yu, L.L. Zhang, X.K. Liu, Y.C. Deng, and M. Zhao, "Electrospun hypromellose-based hydrophilic composites for rapid dissolution of poorly water-soluble drug," Carbohydr. Polym., vol.174, pp.617-625, Oct, 2017.

[12] Y.H. WU, C. Yang, X.Y. Li, J.Y. Zhu, and D.G. Yu, "Medicated nanofibers fabricated using $\mathrm{NaCl}$ solutions as shell fluids in a modified coaxial electrospinning,” J. Nanomater., vol.2016, Article ID 8970213 , 2016.
[13] K. Wang, X.K. Liu, X.H. Chen, D.G. Yu, Y.Y. Yang, and P. Liu, "Electrospun hydrophilic Janus nanocomposites for the rapid onset of therapeutic action of helicid," ACS Appl. Mater. Interfaces, vol.10, pp.2859-2867, 2018.

[14] D.G. Yu, J.J. Li, M. Zhang, and G.R. Williams, "High-quality Janus nanofibers prepared using three-fluid electrospinning," Chem. Commun., vol.53, pp.4542-4545, April 2017.

[15] G.Z. Yang, J.J. Li, D.G. Yu, M.F. He, J.H. Yang, and G.R. Williams, "Nanosized sustained-release drug depots fabricated using modified triaxial electrospinning," Acta Biomater., vol.53, pp.233-241, April 2017.

[16] H.F. Wen, C. Yang, D.G. Yu, X.Y. Li, and D.F. Zhang, "Electrospun zein nanoribbons for treatment of lead-contained wastewater," Chem. Eng. J., vol.290, pp.263-272, April 2016

[17] Y. Xu, J.J. Li, D.G. Yu, G.R. Williams, J.H. Yang, and X. Wang, "Influence of the drug distribution in electrospun gliadin fibers on drugrelease behavior," Eur. J. Pharm. Sci., vol.106, pp.422-430, August 2017.

[18] Z. Zhang, W. Li, G. Wang, Y.L. Qu, and D.G. Yu, "Electrospun 4th generation solid dispersions of poorly water-soluble drug utilizing two different processes," J. Nanomater. Vol.2018, Article ID 2012140 2018.

[19] Q. Wang, D.G. Yu, S.Y. Zhou, C. Li, and M. Zhao, "Fabrication of amorphous electrospun medicated-nanocomposites using a Teflonbased concentric spinneret," e-Polymer, vol.18, pp.3-11, 2018

[20] Y.H. Wu, D.G. Yu, J.J. Li, Q. Wang, H.P. Li, and X.Y. Li, "Medicated multiple-component polymeric nanocomposites fabricated using electrospraying," Polym. Polym. Compos., vol.25, pp.57-62, 2017.

[21] M. Jin, D.G. Yu, X. Wang, C.F.G.C. Geraldes, G.R. Williams, and S.W.A. Bligh, "Electrospun contrast agent-loaded fibers for colontargeted MRI," Adv. Healthcare Mater., vol.5, pp.977-985, April 2016.

[22] I.G. Loscertales, A. Barrero, I. Guerrero, R. Cortijo, M. Marquez, A.M. Canan-Calvo, "Micro/nano encapsulation via electrified coaxial liquid jets," Science vol.295, pp.1695-1698, 2002.

[23] Y. Dzenis, "Spinning continuous fibers for nanotechnology," Science vol. 304, pp.1917-1919, 2004.

[24] C. Yang, D.G. Yu, D. Pan, X.K. Liu, X. Wang, S.W.A. Bligh, et al, "Electrospun pH-sensitive core-shell polymer nanocomposites fabricated using a tri-axial processes," Acta Biomater., vol.35, pp.77-86, April 2016.

[25] X.Y. Li, Z.B. Zheng, D.G. Yu, X.K. Liu, Y.L. Qu, and H.L. Li, "Electrosprayed sperical ethylcellulose nanoparticles for an improved sustained-release profile of anticancer drug," Cellulose, vol.24, pp.5551-5564, 2017

[26] Z.P. Liu, Y.Y. Zhang, D.G. Yu, D. Wu, and H.L. Li, "Fabrication of sustained-release zein nanoparticles via modified coaxial electrospraying,” Chem. Eng. J., vol.334, pp.807-816, 2018.

[27] Y.Y. Yang, M. Zhang, Z.P. Liu, K. Wang, and D.G. Yu, "Meletin sustained-release gliadin nanoparticles prepared via solvent surface modification on blending electrospraying," App. Surf. Sci., vol.434, pp.1040-1047, 2018

[28] K. Wang, H.F. Wen, D.G. Yu, Y. Yang, and D.F. Zhang, "Electrosprayed hydrophilic nanocomposites coated with shellac for colon-specific delayed drug delivery," Mater. Design, vol.143, pp.248$255,2018$.

[29] Z.P. Liu, L.L. Zhang, Y.Y. Yang, D. Wu,G. Jiang, and D.G. Yu, "Preparing composite nanoparticles for immediate drug release by modifying electrohydrodynamic interfaces during electrospraying," Powd. Technol., vol.327, pp.179-187, 2018. 